10 - ORIGINAL ARTICLE

SYSTEMATIC REVIEWS AND META-ANALYSIS

\title{
Single-incision laparoscopic appendectomy versus conventional laparoscopy in adults. A systematic review ${ }^{1}$
}

\author{
Javier Alejandro Moraga Concha ${ }^{\mathrm{I}}$, Ricardo Cartes-Velásquez ${ }^{\mathrm{II}}$, Carlos Manterola Delgado ${ }^{\mathrm{III}}$ \\ DOI: http://dx.doi.org/10.1590/S0102-86502014001900010 \\ ${ }^{\mathrm{I}} \mathrm{MD}$, MSc. Researcher, School of Health Sciences, Universidad Autónoma de Chile. Design of the study, acquisition of data, statistical analysis, \\ manuscript writing. \\ IIDDS, PhD. Academic Collaborator, School of Dentistry, Universidad de Concepción, Chile. Design of the study, acquisition of data, statistical \\ analysis, manuscript writing. \\ IIIPhD, Full Professor, Department of Surgery, Faculty of Medicine, Universidad de La Frontera, Temuco, Chile. Design the study, statistical analysis, \\ manuscript writing, critical revision.
}

\section{ABSTRACT}

PURPOSE: To determine the best treatment option for not complicated acute appendicitis (AA) in adult patients, between single incision laparoscopy (SIL) and conventional laparoscopy (CL), measured by morbidity associated with disease.

METHODS: Systematic review. Articles of adults diagnosed with AA treated by SIL or CL were analyzed. Databases included: MEDLINE, LILACS, IBECS, Web of Science, Scopus and Cochrane, using MeSH terms and free words. The studies were analyzed using the MINCIR methodology. Variables included: conversion rate, morbidity, hospital stay, surgery duration, and methodological quality (MQ) of primary studies. Averages, medians and weighted averages were calculated.

RESULTS: Thirteen articles were analyzed. For SIL and CL the conversion rate were 3.4\% and $0.7 \%$, the morbidity were $8 \%$ and $6.5 \%$, the hospital stay were 2.5 and 2.8 days, the surgery duration were 53.4 and 53.8 minutes, and the MQ were $14.3 \pm 6.6$ and $16.0 \pm 6.9$ points, respectively.

CONCLUSION: With the exception of the conversion rate, there are no differences between single incision laparoscopy and conventional laparoscopy for the treatment of acute appendicitis in adults.

Key words: Appendicitis. Appendectomy. Laparoscopy. Postoperative Complications. Review. 


\section{Introduction}

Acute appendicitis (AA) is one of the clinical presentation of acute surgical abdomen most frequently consulted ${ }^{1,2}$, and corresponds to the condition that goes from appendix inflammation to the cecal appendix perforation. It's treatment consists of the extirpation of the organ itself ${ }^{3}$.

During many years the treatment was carried out by open appendectomy, but this changed with the advent of the first laparoscopic appendectomy carried out by Semm in $1983^{4-6}$. Since then, such procedure would become the treatment of choice for this pathology $y^{7,8}$ because the granted benefits, such as shorter hospital stays, faster recovery and less morbidity and post-surgical pain compared to the traditional open surgery ${ }^{9-12}$.

At present, the surgery has evolved towards less invasive techniques, and laparoscopy has not been the exception. Indeed, nowadays the efforts are aimed to reduce the trauma caused by the procedure and to improve the esthetic results on patients ${ }^{13}$. Innovative methods such as NOTES (Natural Orifice Transluminal Endoscopic Surgery) and single incision laparoscopy (SIL) have demonstrated promissory results in various surgical procedures, appendectomy among them ${ }^{7,14-16}$. There are many articles that report the experience with laparoscopic appendectomy by SIL, the majority of which are series and case reports.

In the last years several systematic reviews (SR) that compares SIL and conventional laparoscopy (CL) have been published ${ }^{6}$. However, all published SR are focused on pediatric or general population and there are no SR comparing both techniques only in adult population. While children and adults share the physiopathology of acute appendicitis, it's clear that have differences arise principally for being completely different terrain. Considering the differences between pediatric and adult in several aspects of AA there is a necessity to analyze the published data in adult patients ${ }^{17}$.

The aim of this study is to determine the best treatment option for not complicated AA, in adults patients, between SIL and CL, measured by morbidity associated with disease.

\section{Methods}

\section{Target population}

Articles on which the population of study was constituted by patients diagnosed with not complicated AA and that have undergone surgery by SIL or CL, published between 2003 and 2013 (both years included).

\section{Eligibility criteria}

Inclusion criteria: Clinical research in patients over 18 years of age, without gender restriction, in Spanish or English language. Due to the scarce number of clinical trials $(\mathrm{CT})$, all types of research designs were considered (case series, transversal cohort studies, historic cohorts, concurrent cohort, CT with random assignment, with or without masking and Multicenter CT).

Exclusion criteria: Studies that considered patients with appendix or cecum cancer, pregnant and with diffuse peritonitis, were excluded. Not available full-text articles, editorials, review articles, letters to the Editor, clinical guidelines, SR, in vitro studies, case reports and case series with less than 20 patients and articles with contaminated sample by any patient that presented any exclusion criteria mentioned above were excluded.

\section{Source databases}

MEDLINE, LILACS, IBECS, Web of Science (WoS), Cochrane Database of Controlled Trials and SCOPUS, between January 2003 and September 2013.

\section{Search strategy}

The sensible search was carried out using $\mathrm{MeSH}$ terms, free words and word truncation. Latter, a specific search was conducted adding boolean operators (OR/AND) and limits (articles published during the last 10 years on humans, in English or Spanish language, on men and women over 18 years of age). The search algorithm used on the MEDLINE database was: ("Appendicitis" [MeSH] OR Append*) AND (Single) AND ("Appendectomy" [MeSH] OR "Laparoscopy" [MeSH] OR Laparoscop*) AND ("Morbidity" [MeSH] OR "Postoperative Complications" $[\mathrm{MeSH}])$. The search was adapted to each one of the remaining databases according to their respective search language.

\section{Study selection}

The articles found, were analyzed by two independent investigators (JM y RC-V), who looked for exclusion criteria on three stages: the first on the title, the second on the abstract and the third on the full-text. 


\section{Data extraction}

From each article, manually by the two investigators mentioned before, for which an ad hoc spreadsheet was design on Microsoft Excel 2007 (Microsoft Corp, Redmond, USA).

\section{Variables}

Number of patients treated, rate of conversion, morbidity and mortality associated with the procedure, hospital stay, surgery duration and score of methodological quality (MQ) of the primary studies.

\section{Methodology quality analysis}

Through the application of the MINCIR therapy scale, which has been recently validated ${ }^{18,19}$ and used to perform SR with an alternative approach ${ }^{20,21}$ similar to El Dib work proposal ${ }^{22}$. Methodological quality (MQ) analysis was performed by two independent investigators (JM and $\mathrm{RC}-\mathrm{V}$ ). Calibration for its implementation took place following the instructions for the use of the MINCIR scale ${ }^{23}$. Discrepancies were solved by consensus.

\section{Definitions}

SIL was defined as laparoscopic appendectomy carried out by a single incision. Includes appendectomies performed with multiport devices and two or three individual ports by a single incision.

\section{Statistical analysis}

Includes averages, medians, extreme values and weighted averages (WA) (Figure 1).

\section{$\mathrm{PP}=\underline{\Sigma \mathrm{Xi}^{*} \mathrm{ei}}$ $\Sigma$ ei}

FIGURE 1 - Calculation of weighted averages.
Calculation of weighted averages. Xi corresponds to the value of the variable in the study $i, e_{i}$ corresponds to the MQ score obtained by the study i, while $\Sigma$ ei corresponds to the sum of MQ score of all studies for that variable

\section{Results}

336 articles were identified ( 82 in MEDLINE, 5 in LILACS, 8 in IBECS, 17 in WoS, 16 in the Cochrane Database of Trials and 208 in SCOPUS). Of these, 13 articles met the selection criteria, so were included and analyzed. The flow diagram of the articles according to PRISMA ${ }^{24}$ is shown in Figure 2.

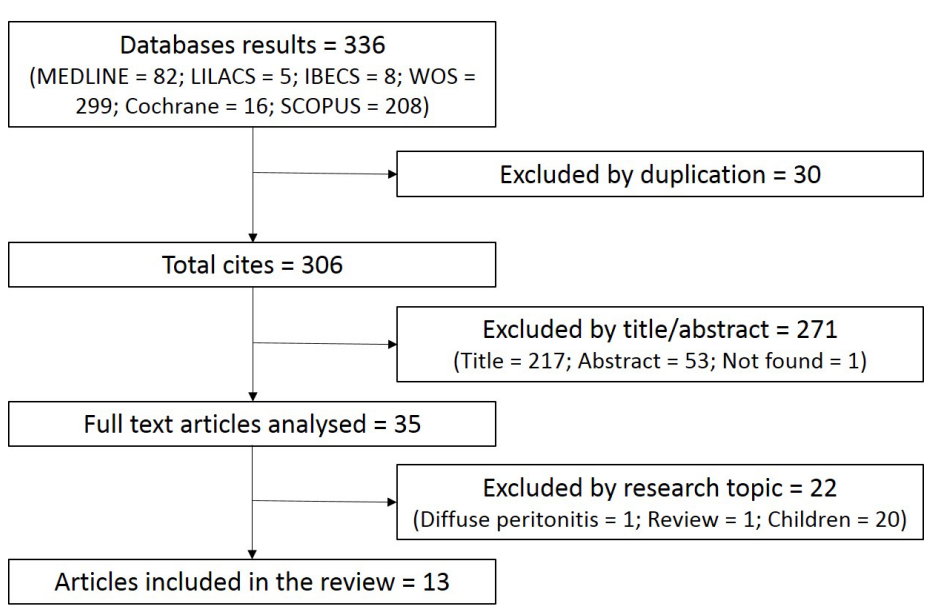

FIGURE 2 - Selection flowchart of articles by PRISMA.

Selected studies correspond to 1 multicenter clinical trial (CT), 4 CT of low quality, 2 cohorts of low quality and 6 case series ( 3 prospective and 3 retrospective), so it was decided to work with series of patients. In this way, studies that carried out comparisons between 2 groups provided with two series of patients. In total, 13 selected studies contributed with 22 series of patients: 4 articles $(30.8 \%)$ constituted series of patients treated by SIL $^{3,16,25,26}$ and 9 articles (69.2\%) are comparative studies between the 2 techniques $5,7,8,13,14,15,27,28,29$.

In total, 816 patients were included: 460 for SIL and 356 for CL.

Table 1 shows the number of series, the number of patients treated and demographic characteristics of each of the studies. 
TABLE 1 - Methodology quality, series and demographic characteristics of studies.

\begin{tabular}{lcccccccc}
\hline \multirow{2}{*}{ Study } & \multirow{2}{*}{$\begin{array}{c}\text { MINCIR } \\
\text { Score }\end{array}$} & N Series & \multicolumn{2}{c}{ N patients } & \multicolumn{2}{c}{ Age } & \multicolumn{2}{c}{ Gender (M:W) } \\
\cline { 3 - 9 } Sozutek 2013 & 21 & 2 & SIL & CL & SIL & CL & SIL & CL \\
\hline Teoh 2012 & 33 & 2 & 98 & 97 & 39.2 & 40.7 & $58: 40$ & $59: 38$ \\
\hline Raakow 2011 & 12 & 2 & 20 & 20 & 27.8 & 31.8 & $8: 12$ & $10: 10$ \\
\hline Teoh 2011 & 13 & 2 & 30 & 60 & 33 & 34.9 & $19: 11$ & $38: 22$ \\
\hline Vidal 2011 & 9 & 1 & 20 & - & 30 & - & $12: 8$ & - \\
\hline Cho 2011 & 11 & 2 & 23 & 20 & 44.7 & 39.2 & $14: 9$ & $11: 9$ \\
\hline Lee 2010 & 11 & 2 & 35 & 37 & 29.6 & 22.3 & $19: 12$ & $11: 21$ \\
\hline Vidal 2010 & 15 & 2 & 15 & 15 & 30 & 36 & $10: 5$ & $9: 6$ \\
\hline Vidal 2010 & 11 & 1 & 52 & - & 30 & - & $32: 20$ & - \\
\hline Park 2012 & 17 & 2 & 42 & 62 & 29.9 & 23.9 & $14: 28$ & $41: 21$ \\
\hline Feinberg 2011 & 8 & 1 & 25 & - & 41 & - & $18: 7$ & - \\
\hline Chouillard 2010 & 10 & 1 & 55 & - & 28 & - & $19: 36$ & - \\
\hline Park 2010 & 15 & 2 & 20 & 20 & 25 & 27.2 & $9: 11$ & $8: 12$ \\
\hline Total & & 22 & 460 & 356 & 32.2 & 31.7 & $244: 212$ & $194: 157$ \\
\hline
\end{tabular}

The conversion rate was higher for SIL, which exceeds nearly by 3 percentage points to the CL. With respect to the morbidity associated with the procedure, its weighted average was slightly higher for SIL than CL (8\% vs. 6.5\%), unlike in mortality which was not reported (no deceases) in any of the studies.

Regarding surgery duration and hospital stay, no significant differences between the two techniques were verified.

Table 2 describes the conversion rate, morbidity associated with the procedure, hospital stay and surgery duration according to type of therapy.

TABLE 2 - Conversion rate weighted average, morbidity associated to the procedure, hospital stay and surgery duration according to the therapy group.

\begin{tabular}{lcccc}
\hline Therapy & $\begin{array}{c}\text { Conversion } \\
(\%)\end{array}$ & $\begin{array}{c}\text { Morbidity } \\
(\%)\end{array}$ & $\begin{array}{c}\text { Hospital } \\
\text { stay (days) }\end{array}$ & $\begin{array}{c}\text { Surgery } \\
\text { duration } \\
\text { (minutes) }\end{array}$ \\
\hline SIL & 3.4 & 8 & 2.5 & 53.4 \\
\hline CL & 0.7 & 6.5 & 2.8 & 53.8 \\
\hline
\end{tabular}

Applying the MINCIR scale for rating MQ, was verified

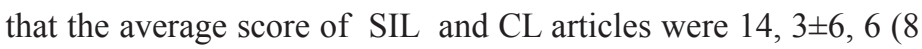

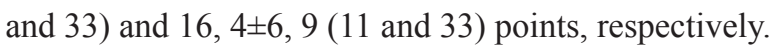

\section{Discussion}

With the passing of years, the surgery has evolved from open surgery to less invasive techniques. One of the landmarks of this evolution was the development of laparoscopic procedures, which would become the standard of reference for multiple procedures $^{7,14-16}$. This development has generated various benefits for patients, fact that is observed as evidence during post-surgey ${ }^{20}$. Laparoscopic surgery has also been subject of evolution: currently, laparoscopic surgery has been developed by a single incision, presenting esthetic unquestionably superior results compared to the conventional laparoscopy. However, there are few studies comparing both techniques in relation with other parameters, such as surgery duration, morbidity associated with the procedure, hospitalization duration, etc. In addition, the existing ones correspond, mostly, to comparative series of retrospective character, in which both pediatric and adult patients are reported. In relation to the above, there is a SR protocol developed by the Cochrane Collaboration, which attempts to compare both techniques in adults, protocol that has been unable to be performed due to the limited availability of CT in this group of patients ${ }^{30}$. This exemplifies the need for evidence of prospective character about this techniques specifically CT of good MQ that support changes on clinical behavior for patients ${ }^{31}$.

As mentioned above, in the absence of sufficient CT to answer the research question, decides to perform this SR using an alternative methodology to the meta-analysis, which uses the weighted average based on the MQ of each of the articles. This allows, following strict selection criteria, to work with different types of research designs, statistically weighted ${ }^{18}$. 
It is important to note that there is considerable heterogeneity in the articles included in this $\mathrm{SR}$ in relation to techniques applied for SIL. This is due to these techniques include the insertion of 3-port devices with a single incision in the fascia and the insertion of independent ports in multiple fascia incisions; in turn, this last ones can count with 2 or 3 trocars.

The conversion rate was found to be higher for SIL, with a difference of nearly 3 percentage points above the CL, probably because surgeons who performed the procedures are still on the stage of training or on the ascending part of the learning curve of the technique. The above has been source of controversy among surgeons, since many argue that the SIL transgresses the principles of laparoscopic surgery by not counting with triangulation, among other features ${ }^{32}$.

No significant differences with regard to morbidity and mortality associated with the procedure, hospital stay and surgery duration between both techniques were observed. This suggests that in relation to this variable, SIL would be equivalent to CL for the treatment of acute appendicitis in patients over 18 years of age.

However, it must be taken into account that the studies used to carried out the present SR are heterogeneous with its MQ, point that must be considered when interpreting the results.

Currently there is little evidence on the safety and effectiveness in relation to the appendectomy by SIL in specific groups, like for example, patients with large number of comorbidities, elderly, obese, complicated acute appendicitis, etc., that could open new and interesting lines of research in the future. Another matter of potential interest are late complications, such as incisional hernias that could be increased by the use of multiport devices that require larger fascia incisions than the traditional trocars. Despite the limitations of the study, we hope to contribute to the choice of a particular therapy for the treatment of not complicated AA based on the available evidence.

In conclusion, the findings of this study allows to indicate that the appendectomy by SIL is comparable to the CL in the treatment of the not complicated AA in adult patients over 18 years of age, in terms of morbidity and mortality associated with the procedure, hospital stay and surgery duration. However, and as mentioned before, further comparative studies (ideally CT of good $\mathrm{MQ}$ ) are necessary to be able to respond in a satisfactory way to the uncertainty that originated this SR.

\section{References}

1. Hasson L, Laurell H, Gunnarsson U. Impact of time in the development of acute appendicitis. Dig Surg. 2008 Dec;25(5):3949. doi:10.1159/000180451.
2. Bejarano M, Gallego C, Gómez J. Frecuencia de abdomen agudo quirúrgico en pacientes que consultan al servicio de urgencias. Rev Colomb Cir. 2011 Jan;26(1):33-41.

3. Vidal O, Ginesta C, Valentini M, Martí J, Benarroch G, GarcíaValdecasas JC. Suprapubic single-incision laparoscopic appendectomy: a nonvisible-scar surgical option. Surg Endosc. 2011 Apr;25(4):1019-23. doi:10.1007/s00464-010-1307-4.

4. Seem K. Endoscopic appendectomy. Endoscopy. 1983 Mar;15(2):5964. doi: 10.1055/s-2007-1021466.

5. Lee J, Baek J, Kim W. Laparoscopic transumbilical single-port appendectomy: Initial experience and comparison with threeport appendectomy. Surg Laparosc Endosc Percutan Tech. 2010 Apr;20(2):100-3. doi: 10.1097/SLE.0b013e3181d84922.

6. Li P, Chen Z, Li Q, Qiao T, Tian Y, Wang DR. Safety and efficacy of single incision laparoscopic surgery for appendectomies: a metaanalysis. World J Gastroenterol. 2013 Jul:19(25);4072-82. doi: 10.3748/wjg.v19.i25.4072.

7. Raakow R, Jacob D. Initial experience in laparoscopic single-port appendectomy: a pilot study. Dig Surg. 2011 Mar;28(1):74-9. doi: $10.1159 / 000322921$.

8. Teoh A, Chiu P, Wong T, Wong S, Lai P, Ng EK. A case controlled comparison of single site access versus conventional three-port laparoscopic appendectomy. Surg Endosc. 2011 May;25(5):1415-9. doi: 10.1007/s00464-010-1406-2.

9. Ortega A, Hunter J, Peters J, Swanstrom L, Schirmer B. A prospective, randomized comparison of laparoscopic appendectomy with open appendectomy. Am J Surg. 1995 Feb;169(2):208-12. doi: 10.1016/S0002-9610(99)80138-X.

10. Ignacio R, Burke R, Spencer D, Bissell C, Dorsainvil C, Lucha PA. Laparoscopic vesus open appendectomy: what is the real difference? Results of a prospective randomized double-blinded trial. Surg Endosc. 2004 Feb;18(2):334-7. doi: 10.1007/s00464-003-8927-x.

11. Aziz O, Athanasiou T, Tekkis P, Purkayastha S, Haddow J, Malinovski V, Paraskeva P, Darzi A. Laparoscopic versus open appendectomy in children: a meta-analysis. Ann Surg. 2006 Jan;243(1):17-27. doi: 10.1097/01.sla.0000193602.74417.14.

12. Frutos M, Abrisqueta J, Luján J, García A, Hernández Q, Valero G, Parrilla P. Apendicectomia laparoscópica mediante incisión única transumbilical: experiencia inicial. Cir Esp. 2011 Jan;89(1):37-41. doi: 10.1016/j.ciresp.2010.09.008.

13. Cho M, Min B, Hong Y, Lee W. Single-site versus conventional laparoscopic appendectomy: comparison of short term operative outcomes. Surg Endosc. 2011 Jan;25(1):36-40. doi: 10.1007/ s00464-010-1124-9.

14. Teoh A, Chiu P, Wong T, Poon M, Wong S, Leong HT, Lai $\mathrm{PB}, \mathrm{Ng}$ EK. A double-blinded randomized controlled trial of laparoendoscopic single-site Access versus conventional 3-port apendectomy. Ann Surg. 2012 Dec;256(6):909-14. doi: 10.1097/ SLA.0b013e3182765fcf.

15. Vidal O, Valentini M, Ginesta C, Martí j, Espert J, Benarroch G, García-Valdecasas JC. Laparoendoscopic single-site Surgery appendectomy. Surg Endosc. 2010 Mar;24(3):686-91. doi: 10.1007/ s00464-009-0661-6.

16. Vidal O, Valentini M, Ginesta C, Espert J, Martí J, Martínez A, Ruiz C, Soliva R, Martrit A, Beññaroch S, García-Valdecasas JC. Apendicetomía laparoscópica con una sola incisión umbilical (SILS): experiencia en una unidad de cirugía de urgencias. Emergencias. 2010 Oct;22(5):361-4.

17. Zavala A, Zavala B, Vera F, Schonhaut L. Apendicitis aguda en el niño. Rev Chil Pediatr. 2012 Oct;83(5):474-81. doi: 10.4067/S037041062012000500010.

18. Manterola C, Pineda V, Vial M, Losada H, Muñoz S. Revisión sistemática de la literatura. Propuesta metodológica para su 
realización. Rev Chil Cir. 2003 Apr;55(2):204-8.

19. Moraga J, Burgos M, Manterola C, Sanhueza A, Cartes-Velasquez R, Urrutia S. Confiabilidad de la escala MINCIR para valorar calidad metodológica de estudios de terapia. Rev Chil Cir. 2013 Jun;65(3):222-7. doi: 10.4067/S0718-40262013000300005.

20. Manterola C, Pineda V, Vial M, Losada H, and the MINCIR group. What Is the methodologic quality of human therapy studies in ISI surgical publications? Ann Surg. 2006 Nov;244(5):827-32. doi: 10.1097/01.sla.0000242708.51631.66.

21. Manterola C, Grande L. Methodological quality of articles on therapeutic procedures published in Cirugía Española. Evaluation of the period 2005-2008. Cir Esp. 2010 Apr;87(4):244-50. doi: 10.1016/j.ciresp.2009.11.008.

22. El Dib R, Nascimento P, Kapoor A. An alternative approach to deal with the absence of clinical trials. A proportional meta-analysis of case series studies. Acta Cir Bras. 2013 Dec;28(12):870-6. doi: 10.1590/S0102-86502013001200010.

23. Moraga J, Manterola C, Cartes-Velasquez R, Burgos M, Aravena P, Urrutia S. Instrucciones para la utilización de la escala MINCIR para valorar calidad metodológica de estudios de terapia. Int J Morphol. 2014 Mar;32(1):294-8. doi: 10.4067/S0717-95022014000100047.

24. Urrútia G, Bonfill X. Declaración PRISMA: una propuesta para mejorar la publicación de revisiones sistemáticas y meta análisis. Med Clin. 2010 Oct;135(11):507-11. doi: 10.1016/j.medcli.2010.01.015.

25. Feinberg E, O'connor D, Feinberg M, Vemulapalli P, Camacho D. Single-incision laparoscopic appendectomy: An early experience. Am Surg. 2011 Mar;77(3):286-89. PMID: 21375838.

26. Chouillard E, Dache A, Torcivia A, Helmy N, Ruseykin I, Gumbs A. Single-incision laparoscopic appendectomy for acute appendicitis: a preliminary experience. Surg Endosc. 2010 Aug;24(8):1861-5. doi: 10.1007/s00464-009-0860-1.

27. Park J, Kwak H, Kim S, Lee S. Single-port laparoscopic appendectomy: Comparison with conventional laparoscopic appendectomy. J Laparoendosc Adv Surg Tech. 2012 Mar;22(2):1425. doi: 10.1089/lap.2011.0253.

28. Park J, Hyun K, Park C, Choi S, Choi W, Kim D, Lee S, Kim J. Laparoscopic vs transumbilical single-port laparoscopic appendectomy: results of prospective randomized trial. J Korean Surg Soc. 2010 Dec;78(4):213-8. doi: 10.4174/jkss.2010.78.4.213.

29. Sozutek A, Colak T, Dirlik M, Ocal K, Turkmenoglu O, Dag A. A prospective randomized comparison of single-port laparoscopic procedure with open and standard 3-port laparoscopic procedures in the treatment of acute appendicitis. Surg Laparosc Endosc Percutan Tech. 2013 Feb;23(1):74-8. doi: 10.1097/SLE.0b013e3182754543.
30. Rehman H, Rao A, Ahmed I. Single incision versus conventional multi-incision appendicectomy for suspected appendicitis (Review). Cochrane Database Syst Rev. 2011 Jan;7:CD009022. doi: 10.1002/14651858.CD009022.pub2.

31. St. Peter S, Ostlie D. The necessity for prospective evidence for single-site umbilical laparoscopic surgery. Semin Pediatr Surg. 2011 Nov;20(4):232-6. doi: 10.1053/j.sempedsurg.2011.05.008.

32. Markar S, Karthikesalingam A, Di Franco F, Harris A. Systematic review and meta-analysis of single-incision versus conventional multiport appendicectomy. Br J Surg. 2013 Dec;100(13):1709-18. doi: 10.1002/bjs.9296.

\section{Correspondence:}

Javier Moraga Concha

Rio Guadiana 8250

Las Condes, Santiago - Chile

Phone: +5622567 6458/+56 977575016

javier.moragac@gmail.com

Received: Aug 19, 2014

Review: Oct 17, 2014

Accepted: Nov 21, 2014

Conflict of interest: none

Financial source: none

${ }^{1}$ Research performed at Center of Research in Biomedical Sciences, School of Health Sciences, Universidad Autónoma de Chile. 